\title{
A new method of building permeability model in low-permeability reservoir numerical simulation
}

\author{
Yong-Chao Xue ${ }^{1}$, Lin-Song Cheng ${ }^{1}$, Lei $\mathrm{Su}^{2}$ \\ ${ }^{1}$ CMOE Key Laboratory of Petroleum Engineering in China University of Petroleum, Beijing, China; xyc75@163.com \\ ${ }^{2}$ The institute of Exploration and Development of LiaoHe oil Field, Panjin, China
}

Received 22 October 2009; revised 24 November 2009; accepted 15 December 2009.

\begin{abstract}
Aiming at solving the problem that big difference exists between logging permeability and true permeability of micro-fractured lowpermeability sand reservoir, this paper puts forward a new method to revise logging permeability by using primiparity data of oil field. This method has been successfully applied to revise logging permeability of micro-fractured low-permeability sand reservoir in Baiyushan area of Jing'An oil field, which shows that the method is reliable because the geological model building through the permeability which has been handled by this method accords with the real reservoir significantly.
\end{abstract}

Keywords: Logging Permeability; Micro-Fractured; Low-Permeability Reservoir; Revise

\section{INTRODUCTION}

In recent years, about 60 to 70 percent of discovered reserves are low-permeability ones, it's anticipated that most of discovered reserves in the future will be low-permeability reservoir, how to develop it efficiently is getting counted [1-3]. Development plan and effect are determined by the performance characteristic research of low permeability reservoir, permeability is a key factor characterizing fluid flow. There are lots of problems in the evaluation of permeability in micro-fractured lowpermeability reservoir. The relationship between logging and core analysis permeability, which is caused by developed fracture, is too complicated to be used in reservoir engineering and numerical simulation [4-5]. Due to non-linear fluid flow, the actual flow characteristics of reservoir couldn't be reflected by logging permeability and core permeability correctly. For solving reservoir performance evaluation of oil field development production, the performance permeability used in research, the actual flow characteristics of reservoir could be reflected by which of test and primiparity data, is very important for logging permeability corrected method.

\section{AIBRATION CLCULATION POCEDURE OF LGGING PRMEABILITY}

\subsection{Calculating Reservoir Permeability Using Primiparity Data Files}

Since particularity of micro-fracture in low-permeability reservoir, if logging permeability is used for reservoir engineering evaluation and numerical simulation calculation directly, severe deviation will occur, causing the inaccuracy of result. However, reservoir development performance is the objective behavior of reservoir actual flow characteristic. Performance permeability, calculated by reservoir development performance files, is the true permeability in reservoir. During oil field production, well yield [4] is usually calculated by the equation of radius fluid flow deliverability. On the contrary, reservoir performance permeability is solved by that equation, concrete Equation is written below [6-10]:

$$
K_{\mathrm{T}}=\frac{Q \cdot \mu \cdot \ln \frac{r_{\mathrm{e}}}{r_{\mathrm{w}}}}{2 \pi \cdot h \cdot \Delta P}
$$

where $K_{\mathrm{T}}$ is reservoir dynamic permeability, $\mu \mathrm{m}^{2} ; Q$ is well yield, $\mathrm{cm}^{3} / \mathrm{s}(\mathrm{sub}) ; \mu$ is oil viscosity in formation, $\mathrm{mPa} \mathrm{s} ; r_{\mathrm{e}}$ is supply radius, $\mathrm{cm} ; r_{\mathrm{w}}$ is oil well radius, $\mathrm{cm}$; $h$ is reservoir thickness, $\mathrm{cm}$.

For the convenience of calculation, standard units of Darcy law are used in the variables above. When practically applied, well yield needs to be conversed to subsurface volume with volume factor. Half of well spacing could be substituted for $r_{\mathrm{e}}$, because $r_{\mathrm{e}}$ is in the range of logarithm, with small effect on the results.

\subsection{The Calculation of Reservoir Logging Permeability}

The result of sequent point by point treatment in log interpretation model is usually used for logging perme- 
ability, since the interval of log sample density is $0.125 \mathrm{~m}$, and performance permeability calculated by actual production files is located in some production interval, there is asymmetry between them. Logging permeability in target stratum must be averaged by actual production intervals, in order to build corresponding relationship with the permeability of actual production intervals. The permeability expression of actual production intervals calculated by average method of logging permeability is described below:

$$
\bar{K}_{\mathrm{L}}=\frac{\sum_{i=1}^{n_{2}}\left[\frac{\sum_{j=1}^{n_{1}} K\left(\phi, M z, V_{\mathrm{sh}}\right)_{j}}{n_{1}}\right] \cdot h_{i}}{h}
$$

where $\bar{K}_{\mathrm{L}}$ is the average logging permeability of reservoir production intervals, $\mu \mathrm{m}^{2} ; K\left(\phi, M z, V_{\mathrm{sh}}\right)_{j}$ is the permeability of $j$ sample site in $i$ sublayer, $\mu \mathrm{m}^{2} ; \varphi, M z$, $V_{\mathrm{sh}}$ is the porosity, the median grain diameter, the shale content of $j$ sample site in $i$ sublayer; $h_{\mathrm{i}}$ is the thickness of reservoir production intervals, $\mathrm{m} ; n_{1}$ is the number of logging permeability point in $i$ sublayer; $n_{2}$ is the number of sublayer in piezometric intervals.

\subsection{The Correction of Logging Permeability}

Reservoir performance permeability, calculated by primiparity data files, could reflect the actual flow characteristics in reservoir, which is closer to the true one. Because there is great distinction between logging permeability and performance permeability in fractural low-permeability reservoir, when logging permeability is corrected by performance permeability, the correction coefficient $\lambda$ has to be introduced, the $\lambda$ can be calculated by Formula 3:

$$
\lambda=\frac{K_{\mathrm{T}}}{\bar{K}_{\mathrm{L}}}=\frac{\frac{Q \cdot \mu \cdot \ln \frac{r_{\mathrm{e}}}{r_{\mathrm{w}}}}{2 \pi \cdot h \cdot \Delta P}}{\sum_{i=1}^{n_{2}}\left[\frac{\left.\sum_{j=1}^{n_{1}} K\left(\phi, M z, V_{\mathrm{sh}}\right)_{j}\right]}{n_{1}}\right] \cdot h_{i}}
$$

where $\lambda$ is correction coefficient which is revise logging permeability to performance permeability, the values varies by wells. The greater of $\lambda$, the more difference between logging permeability and performance permeability, the logging permeability can't reflect reservoir effluent seepage characteristic. The less of $\lambda$, the less difference between logging permeability and per- formance permeability, the logging permeability can approximately reflect reservoir effluent seepage characteristic.

As to every production well, only one $\lambda$ value can be calculated by Formula 3, but, when building 3D permeability model, the every point logging permeability need to be revised. Only using every point revised permeability, the 3D permeability model can better reflect reservoir actually effluent seepage characteristic. So the Formula 4, dynamic correction model of logging permeability, can be used to correction every point logging permeability.

$$
\text { Perm }=\lambda \times K\left(\phi, M z, V_{\text {sh }}\right)
$$

where Perm is logging permeability after performance correction, for reservoir permeability model, $\mu \mathrm{m}^{2}$;

With the value of $\lambda$, logging permeability of each well could be corrected to performance permeability point by point, then performance permeability model, which is closer to the true reservoir, would be established for the research of reservoir engineering and numerical simulation.

When using this method, the problems below should be noticed. 1) In order to ensure that only single phase flow occurs, initial production should be taken as possible; 2) Well flow rate must be conversed to sand face one by volume factor; 3) Don't use multiple zones commingled test data; 4) If the area of reservoir is large, fluid viscosity varies, it needs to be treated zone by zone.

\section{APPLICATION}

In this paper, Chang $4+5$ reservoir in Baiyushan area of Jing'An oil field is chosen as an example. Baiyushan area of Jing'An oil field is situated at NE-SW nose like structure on the Shanbei slope of Ordos basin, Chang $4+5$ reservoir is generally delta front subfacies deposite, major reservoir is subsea distributary channel sand, most of reservoir lithology are fine sandstone, siltstone and argillaceous siltstone; Major reservoir sand type is lithic arkose; The average porosity of reservoir is $12.4 \%$, the average permeability of reservoir is $1.05 \times 10^{-3} \mu^{2}$, it's a typical sand reservoir with low porosity and permeability. Structural microfracture developed in reservoir has been discovered during production. When production history is matched with the model established by logging permeability, no matter how to regulate relative permeability, it's shown that match water injection is smaller than true one, match oil production is smaller than true one.

According to logging permeability correction method above, logging permeability performance correction coefficient $\lambda$ of wells in region of interest were calculated (Table 1, partial wells shown). From Table 1: it's seen that great difference exists between performance 
Table 1. Log interpretation permeability dynamic correction coefficient.

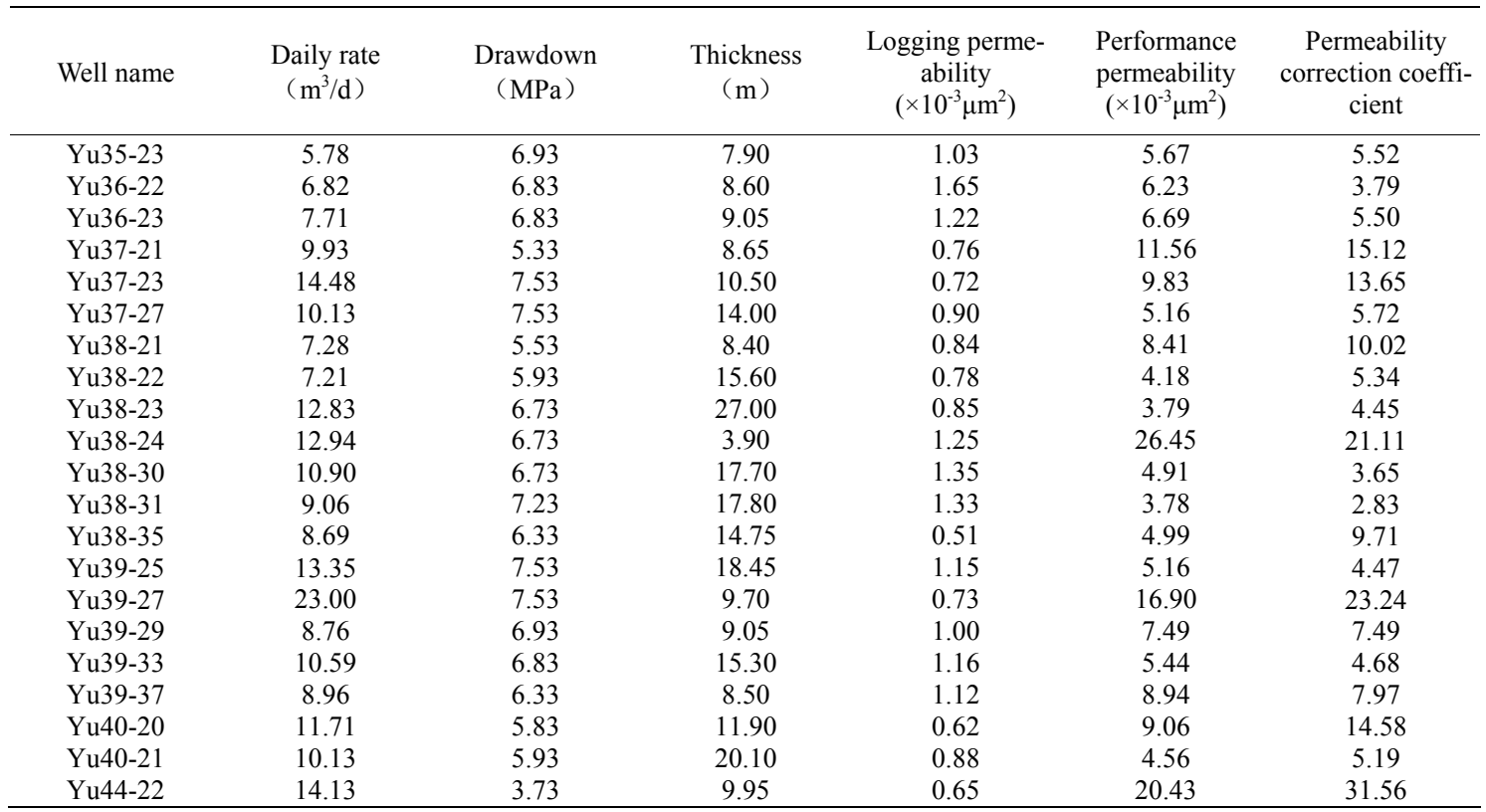

permeability and logging permeability. The biggest was 31.56 times, the smallest was 2.83 times, 5 to 10 times is in general. It was clarified that logging permeability was much smaller than performance one, true flow charac teristics of reservoir couldn't be reflected. On the other

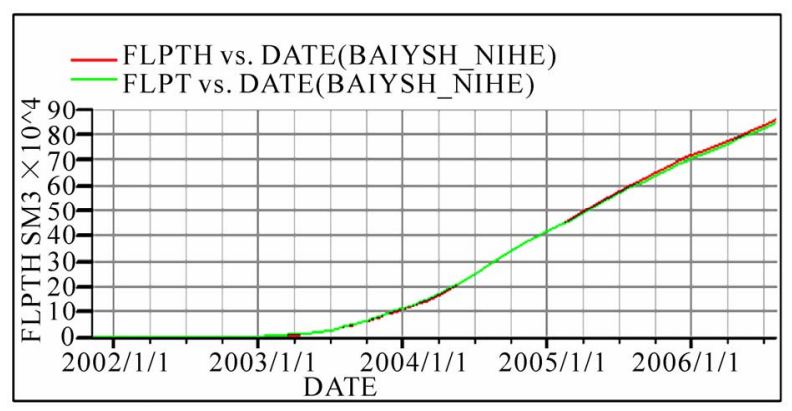

FLPTH: field liquid production total history, FLPT: field liquid production total (model)

(a) Cumulative liquid production

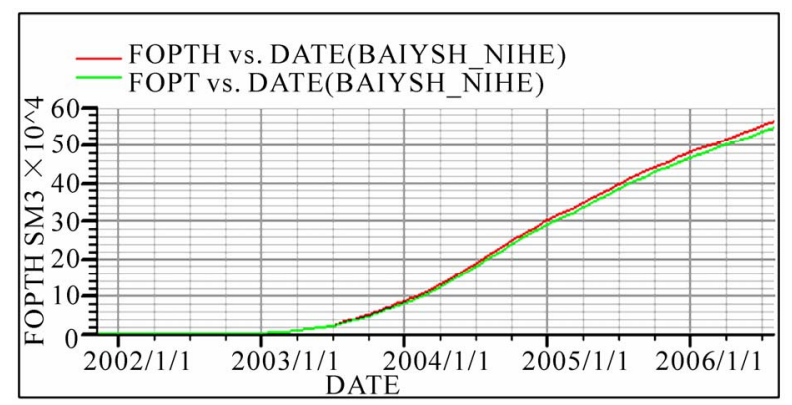

FOPTH: field oil production total history, FOPT: field oil production total (model)

(b) Cumulative oil production

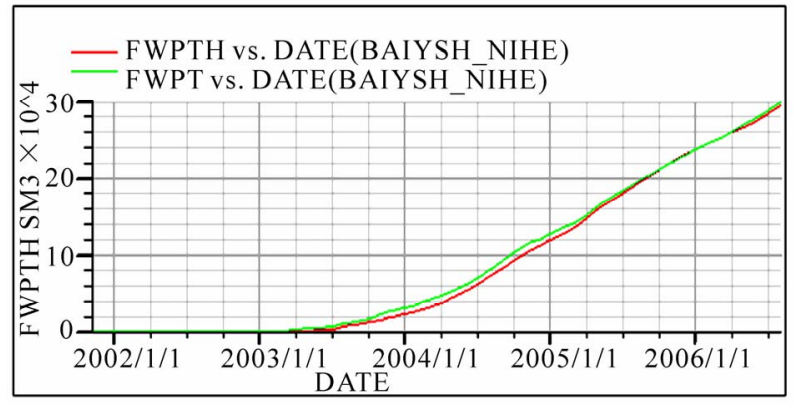

FWPTH: field water production total history, FWPTH: field water production total (model)

(c) Cumulative water production

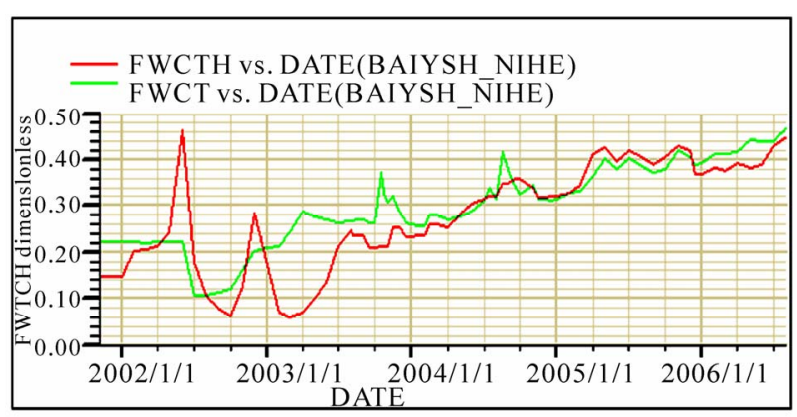

FWCTH: field water cut total history, FWCTH: field water cut total (model)

(d) Composite water cut

Figure 1. Development history marching curve of Baiyushan Chang4+5 reservoir in Jing' an oil field.

hand, it was the reason why the actual development of reservoir couldn't be matched using permeability model established by logging permeability directly. 
According to the logging permeability correction coefficient of each well, the logging permeability of each well were corrected point by point $(0.125 \mathrm{p} / \mathrm{m})$, then the dynamic corrected logging permeability of each well were yielded. On basis of it, permeability model of reservoir numerical simulation was established, and producing history was matched. Chart 1 is the result of history match. From the chart 1 , we can conclude that, the field liquid production total history is $86.00 \times 10^{4} \mathrm{~m}^{3}$, history match is $84.98 \times 10^{4} \mathrm{~m}^{3}$, error is $1.19 \%$ (Figure 1(a)); field oil production total history is $49.00 \times 10^{4} \mathrm{~m}^{3}$, history match is $47.65 \times 10^{4} \mathrm{~m}^{3}$, error is $2.76 \%$ (Figure $1(\mathbf{b})$ ); field water production total history is $29.44 \times 10^{4} \mathrm{~m}^{3}$, history match is $29.98 \times 10^{4} \mathrm{~m}^{3}$, error is $1.84 \%$ (Figure 1(c)); field water cut total history is $34.2 \%$, history match is $35.3 \%$, error is $3.22 \%$ (Figure 1(d)); moreover, all the producing history procedure match better (Figure 1), the reservoir numerical simulation accuracy requirement is met. It was shown that the method was more coincide with oil field production, better effect of matching.

\section{CONCLUSIONS}

1) Aiming at the evaluation problem of log interpretation permeability in micro-fractured low permeability reservoir, the correction method of logging permeability using oil field development performance files was proposed, then numerical simulation model, which is closer to the actual permeability in reservoir, was established. The method had a good effect on Baiyushan area of Jing'An oil field.

2) Reservoir numerical simulation model, established by development performance files, is favour of the improvement of reservoir numerical simulation reliability.

\section{REFERENCES}

[1] Li, D.P. (1997) Low-permeability sand reservoir development [M]. Beijing, Petroleum Industry Press, 14-17.

[2] Qiu. Y.N. (1998) Low permeability sand reservoir development mode $[\mathrm{M}]$. Beijing, Petroleum Industry Press, 23-25.

[3] Li, H.N., Xu, H.M. and Xu, N. (2006) The heterogeneity model of low permeability reservoir and remaining oil distribution $[\mathrm{J}]$. petroleum geology \& experiment, 28(4), 404-408.

[4] Zhai, Y.F. (1999) Fluid mechanics in porous medium [M]. Beijing, Petroleum Industry Press, 61-79.

[5] Jia, Z.Q., Sun, N. and Wu, J.C. (2009) Experimental study on relative permeability of super-low permeability cores [J]. Special Oil and Gas Reservoirs, 16(1), 81-83.

[6] Song, S.M. and Wang, Y.Z. (2004) Using geologic strata data to symbolize oil reservoirs geology model [J]. Well Testing, 13(6), 17-19.

[7] Yin, H.J, Zhang, R.L. and Fu, C.Q. (2008) Transient pressure calculation for low permeability homogeneous reservoirs [J]. Special Oil and Gas Reservoirs, 15(5), 50-52.

[8] Chen, G.L., Liang, C.X. and Liu, Z.L. (2004) Optimization of the flooding pattern in reservoirs with obvious directions of fracture and sand body $[\mathrm{J}]$. Petroleum exploration and development, 31(4), 112-115.

[9] An, X.P., Li, X.F., Cheng, S.Q., ect. (2004) Comparative analysis for permeability acquired from different methods [J]. Well Testing, 13(6), 17-19, 2005, 14(5), 14-17.

[10] Ma, F.J., Hu, J.C. and Zhuang, J. (2005) Advanced water injection in low permeability reservoir of block Xin19 [J]. Special Oil and Gas Reservoirs, 12(3), 47-51. 